\title{
CONHECER EM MARX
}

RESUMO: O presente trabalho tem por objetivo a exposição da metodologia do conhecimento em Marx. Método entendido aqui em sentido amplo, como caminho, peregrinação científica. Para tanto, partir-se-á do debate doutrinário instaurado em que se controvertem duas posições: primazia da consciência sobre a realidade - posição chamada de filosofia do sujeito - ou primazia do objeto sobre a consciência - posição marxista. Neste contexto, e com apoio em Marx, serão aportadas algumas considerações que podem servir de diretrizes à solução desse conflito.

Palavras-Chave: Metodologia Científica. Sujeito. Objeto.

\section{MEET IN MARX}

ABSTRACT: The present work aims an exposition of the methodology of knowledge in Marx. Method understood here in a broad sense, as a way, scientific pilgrimage. We will start from the established doctrinal debate in which two institutions are controverted: primacy of the conscience over reality - position called the philosophy of the subject - or primacy of the object over a consciousness - Marxist position. In this context, and with support in Marx, some considerations are given that can serve as guidelines for the solution of this conflict.

Keywords: Scientific Methodology. Subject. Object.

\section{INTRODUÇÃO}

O debate doutrinário que se forma entre duas posições antagônicas - a primazia da consciência sobre a formação do objeto do conhecimento ou a primazia do objeto sobre a formação do sujeito não é nova e, a bem da verdade, tem suas origens antes mesmo de sua emergência. Mas é na controvérsia instaurada por Weber (2006) contra a posição de Marx (2005) que ela ganha contornos mais precisos. Opondo-se ao idealismo alemão, particularmente o (neo) hegelianismo, Marx (2005, p. 52) faz uma afirmação que, depois, dará fundamento à posição marxista de primazia do objeto sobre o sujeito: "Não é a consciência que determina a vida, mas a vida é que determina a consciência”. A partir dessa constatação, há uma fecundidade de consequências inevitáveis acerca da concepção de história:

\footnotetext{
${ }^{1}$ Pós-Graduado em Integração Econômica e Direito Internacional Fiscal pela FGV/UE e mestrando de Sociedade, Cultura e Fronteiras pela Universidade do Oeste do Paraná - UNIOESTE . Atualmente é professor do
} 
Não se trata, como na concepção idealista da história, de buscar uma categoria em cada período, mas sim de permanecer sempre no solo real da história; não de explicar a práxis a partir da ideia, mas de explicitar as formações ideológicas a partir da práxis material; chega-se, em consequência disso, ao resultado de que todas as formas e todos os produtos da consciência não podem ser resolvidos por força da crítica espiritual (intelectual), pela redução à "consciência de si" ou pela transformação em "fantasmas", "obsessões", "visões", etc. - mas só podem ser dissolvidos pela derrubada prática das relações reais das quais brotam essas tapeações idealistas; não é a crítica, mas a revolução, a força motriz da história, assim como da religião, da filosofia e de qualquer outro tipo de teoria. (MARX, 2005, p. 66)

Tem-se assim que o motor fundamental da história é a revolução, vale dizer que a realidade só pode ser transformada e compreendida pela ação do homem: conhecer e agir são dois momentos necessários e que se exigem reciprocamente, e, por isso mesmo, todo homem que conhece deve "macular-se" materialmente, impregnar-se do mundo sensível.

A concepção marxiana não passou livre de críticas, particularmente de neo-kantistas como Weber. Para Weber (2006), partindo de uma posição subjetivista, a realidade é caótica, ante a infinitude de elementos particulares que a compõe, e que o conhecimento só pode se referir a uma pequena parcela da realidade, eleita valorativamente pelo sujeito. Nesses termos, o sujeito cognoscente não deve interferir nos fatos, os quais devem ser analisados objetivamente, não sujeitos a julgamentos de valor. A única valoração possível ao homem que conhece se refere à escolha da parcela da realidade que pretende estudar. Essa escolha pode basear-se em preferências pessoais, mas, feita a eleição, o distanciamento dos fatos é o que garante o rigor da objetividade no conhecer.

Ao proceder sua crítica ao reducionismo do conhecimento às causas econômicas, Weber (2006) está claramente mirando seu arsenal teórico à concepção marxista. Com isso, Weber (2006) entende que o objeto da ciência não são as conexões entre coisas, mas sim conexões conceituais entre os prolemas, o que leva necessariamente à recusa de uma caracterização materialista do conhecimento. O conhecimento é, antes, uma formulação nomológica, pela qual o sujeito cognoscente tipifica as regularidades encontráveis na realidade caótica.

Como visto, esse embate marxiano-weberiano não se esgota, portanto, no campo gnoseológico, que é apenas um dos aspectos da questão. Mas, indubitavelmente, tem repercussões significativas na esfera do conhecimento humano, que podem ser sintetizada 
com Tonet (2013, p. 13), nos seguintes termos:

\begin{abstract}
A problemática do conhecimento se resume, em seus termos mais essenciais, à relação entre um sujeito e um objeto. Simplificando, ainda, podemos dizer que, nessa relação, o peso maior (prioridade) pode estar do lado do sujeito ou do objeto. No primeiro caso teremos um ponto de vista gnosiológico. No segundo caso, um ponto de vista ontológico. Trata-se, portanto, aqui da resposta à pergunta: quem é o polo regente do processo de conhecimento?
\end{abstract}

A crítica de weberiana à posição marxiana é tributária de uma corrente de pensamento que enfatiza a posição do sujeito relativamente ao objeto, corrente essa que pode ser chamada "filosofia do sujeito". Embora não deixe de ser um tanto arbitrária a tipificação da filosofia do sujeito como corrente de pensamento, já que não se trata de pensamentos unívocos, há alguns pontos de coincidência que, para fins práticos, permitem essa caracterização. Em comum, essas concepções assinalam a subordinação do conhecimento aos preceitos da razão. A revolução copérnica, proposta por Kant (2009) é um ponto de inflexão decisivo. Se Copérnico fez desmoronar a cosmologia antiga, baseada no geocentrismo do universo, substituindo-a pelo heliocentrismo, Kant (2009) promoveu o sujeito cognoscente como centro de toda possibilidade de conhecimento. Não é em torno do ser, ontologicamente determinado - tal como concebido pela metafísica da antiguidade -, que gravitaria o conhecimento desde então, mas em volta do sujeito cognoscente é que os objetos do conhecimento orbitariam. Em sua Crítica da Razão Pura, Kant (2009) apregoa que a possibilidade de conhecimento se dá graças a condicionantes transcendentais, que não estão postas na realidade, mas sim na própria natureza humana. Essas categorias são as responsáveis pela determinação da forma dos fenômenos, ordenando a realidade que se nos chega pela sensibilidade provocada pelos objetos do conhecimento. $\mathrm{O}$ que o sujeito conhece, por conseguinte, não é a realidade, mas a si mesmo, ou as sensações provocadas pela experiência, que tomam forma racional graças às categorias inerentes à razão humana.

A questão que subjaz é a liberdade. Ao tentar fugir do aprisionamento causal dos fatos imposto pelo determinismo humeniano, Kant (2009) é obrigado a fazer uma concessão para conservar a liberdade do indivíduo: jamais tocar a realidade com seu conhecimento. A maldição kantiana tem duras consequências, pois o indivíduo que conhece nunca poderá conhecer a coisa-em-si, mas apenas as sensações provocadas pela coisa. No ato de conhecer, o sujeito cognoscente desce de seu mundo transcendental para contemplar a experiência, mas 
sem jamais sujar os pés no chão da realidade. Os juízos universais, destituídos de uma verdade histórica, assinalam os limites da razão. O conhecimento forma-se por meio de um processo silogistico a partir dos juízos universais determinados pela razão e dos quais derivariam dedutivamente os juízos regionais, numa contínua expansão racional "para dentro".

Se o sujeito é o centro de gravitação de conhecimento, se não é a realidade que produz a consciência, mas razão que produz a realidade, é inevitável que o objeto do conhecimento deve se subordinar aos ditames da razão. Há uma primazia do sujeito sobre o objeto, pois é a consciência que produz os objetos que pretende conhecer. Com isso, o kantismo não só sentenciava o fim da metafísica do conhecer, tal como concebida desde a antiguidade a produção do conhecimento, mas também expurgou a ontologia dos lindes filosóficos, pois a questão fundamental não mais o que conhecer, mas sim o que posso conhecer, até onde posso ir com a razão. Em suma dessa posição, e mais uma vez com apoio em Tonet (2013, p. 13):

Ponto de vista gnosiológico é, pois, a abordagem de qualquer objeto a ser conhecido que tem como eixo o sujeito. Lembrando a chamada "revolução copérnica" levada a cabo por Kant, podemos dizer que, neste ponto de vista, é o sujeito o elemento central. Em vez de o sujeito girar ao redor do objeto, como no caso da concepção greco-medieval,, aqui é o objeto que gira ao redor do sujeito. Enfatiza-se, nesse caso, não só o caráter ativo do sujeito no processo de conhecimento, mas especialmente, o fato de que é ele que constrói (teoricamente) o objeto. O sujeito é o polo regente do processo de conhecimento. É ele que colhe os dados, classifica, ordena, organiza, estabelece as relações entre eles e, desse modo, diz o que o objeto é.

À filosofia do sujeito opõem-se as concepções marxistas que pregam a primazia do objeto sobre o sujeito, levando a cabo a afirmação de Marx (2005) de que a vida produz a consciência. Especialmente fundada sob uma epistemologia crítica sob perspectiva materialista, pode-se afirmar, juntamente a Faria (2015, p. 92) que:

(...) o método de produção de conhecimento tem por fundamento a primazia do real sobre a ideia, mas, para que o real possa ser apropriado pela consciência, necessita da mediação do pensamento, recusando, dessa forma, tanto o empirismo como o idealismo. A inscrição da matéria na consciência mediada pelo pensamento não se constitui nem em uma tradução direta, sem intermediação, nem em uma elaboração metafísica, mas em uma interação dialética, tensionada e dinâmica, marcada pela complexidade e pelas contradições entre o sujeito e o objeto. 
A primazia da realidade sobre a consciência assinala a primazia do objeto sobre o sujeito, uma vez que o sujeito só pode conhecer enquanto ser efetivo, que interage com a realidade, por meio de sua atividade laborativa. Nesse contexto, os objetos do conhecimento não são construídos pelo sujeito, mas por ele interpretados de acordo com sua real significação, vale dizer, de acordo com sua significação ontológica. Recusando o idealismo alemão em geral, e particularmente o hegeliano, que reduz o sujeito a uma instância abstrata, um espírito que se absolutiza por uma peregrinação cerebrina, na qual os objetos são ideados na consciência absoluta, as correntes marxistas priorizam o objeto sensível, forjado no âmbito de um processo relacional do homem com a natureza, pelo qual a consciência emerge subjetivada. É na simbiose do homem com a natureza, que lhe faz as vezes de corpo orgânico, que o homem transforma a natureza humana, pela mediação do trabalho: objetivando a natureza, o homem se subjetiva.

A subjetivação está, entretanto, sempre subordinada à configuração da realidade, particularmente às condições de produção da vida, às forças produtivas, aos meios de produção, às condições de sociabilidade, à existência de classes sociais, etc. E é nesse sentido que o sujeito se subordina ao objeto, ou a consciência se subordina à realidade, pois são as condições da vida que determinam a forma de manifestação específica do ser social.

Trata-se de recuperar o caráter ontológico do pensamento, fundando-o não mais em concepções metafísicas, mas em bases sociais e histórica: uma ontologia do ser social. Apropriando-se novamente do poder de síntese de Tonet (2013, p. 14):

Ponto de vista ontológico é, por sua vez, a abordagem de qualquer objeto tendo como eixo o próprio objeto. Lembrando, porém, que a ontologia é apenas a captura das determinações mais gerais e essenciais do ser (geral ou particular) e não, ainda, da sua concretude integral. Deste modo, a captura do próprio objeto implica o pressuposto de que ele não se resume aos elementos empíricos, mas também, e principalmente, àqueles que constituem sua essência. Ainda independentemente de ser uma ontologia de caráter metafísico ou histórico-social, o ponto de vista ontológico implica a subordinação do sujeito ao objeto, vale dizer que, no processo de conhecimento, o elemento central é o objeto. Neste sentido, não cabe ao sujeito criar - teoricamente - o objeto, mas traduzir, sob a forma de conceitos, a realidade do próprio objeto.

Ainda em linhas introdutórias, uma terceira via pode se apresentar: aquela que prega a inexistência de subordinação de sujeito a objeto ou do objeto ao sujeito. Trata-se de uma concepção ontognoseológica pela qual tanto sujeito como objeto estão no mesmo patamar, e só pela recíproca exigência desses dois polos pode fundar-se o conhecimento. Fundada em 
posição culturalista, e admite que cultura e natureza sejam instâncias distintas, mas inseparáveis. Sobre o mundo dado, o homem constrói a cultura, constrói objetos culturais cujos significados deve compreender. Toda produção humana tem uma finalidade, tem um significado valorativo e, por isso mesmo, a realidade cultural só pode ser compreendida em suas conexões de sentido. Mas quanto ao mundo dado, o mundo natural, esse cabe explicação de suas relações causais: o mundo natural é o mundo do ser, enquanto que o mundo cultural é o do dever-ser. Essa posição é assumida por exemplo, por Reale (1994, p. 126) e pode ser sintetizada da seguinte forma:

Sujeito cognoscente e "algo real" são elementos essenciais a qualquer conhecimento do mundo, da natureza e da cultura, isto é, de quanto não seja conhecimento de meros objetos ideais, como os da Matemática e da Lógica. Consideramos algo (aliquid) tudo que seja suscetível tornar-se objeto. Se no plano dos objeto ideais há uma identidade entre "algo" e "objeto", que se distinguem apenas como posições do pensamento mesmo, já os objetos naturais ou culturais suscitam o problema da adequação entre um e outro, entre o que é objeto (conteúdo de pensamento) e algo extrínseco ao pensamento, a que o pensamento se dirige, em uma "intencionalidade" que é traço essencial da consciência, consoante o renovado ensinamento de Husserl. Situando-se perante algo, o sujeito põe logicamente o objeto, mas só o põe na medida em que o converte em estruturas "lógicas" as estruturas "ônticas" de algo. O sujeito é, assim, uma energia reveladora de determinações só logicamente possíveis por haver em "algo" virtualidades de determinação. Daí dizermos que o conhecimento é um construído de natureza "ontognoseológica".

Para Reale (1994), sujeito e objeto são polos que se exigem reciprocamente e se implicam em um processo dialético de implicação e polaridade, pelo qual tese e antítese não se extinguem para dar lugar a uma síntese, mas sim há, no mundo da cultura, valores positivos e negativos que se tensionam e se implicam, compondo-se normativamente, sem que qualquer desses elementos se esgotem um no outro. Ao contrário da dialética hegeliana, que se funda em termos contrários e contraditórios que se aniquilam, Reale (1994) sustenta que a dialética de implicação e polaridade, na qual se baseia o método histórico-axiológico, funda-se na natureza ambivalente dos valores, que sempre podem assumir uma posição negativa ou positiva, como abstrato-concreto, universarl-particular, estático-dinâmico, etc, sem que haja necessidade de esgotamento, dada a inexauribilidade do valor-fonte, que é o ser humano. Sendo a cultura o resultado da histórica cristalização de valores, só pela coimplicação de sujeito e objeto dialeticamente compostos pode fundar-se o conhecimento humano.

\section{CONHECIMENTO A PARTIR DA MARX}


Para mediar esse imbróglio, chama-se a lume o pensamento marxiano. Para tanto, faz-se mister contextualizar a sua famosa e já citada frase de que não seria a consciência a determinante da vida, mas sim a vida a determinante da consciência (MARX, 2005). A frase contrapunha-se ao estado da filosofia alemã à época ${ }^{2}$, conduzida especialmente pelos neohegelianos, que pregavam o domínio das ideias sobre a realidade e, nesse passo, para mudar a realidade bastaria mudar a consciência. Em sua crítica, Marx (2005) decide partir de bases reais, empiricamente verificáveis: indivíduos reais, sua ação e suas condições de vida encontradas já elaboradas ou produzidas pelo homem. Nesta ordem de ideias, o primeiro pressuposto é a própria existência de seres humanos vivos, o que leva à necessidade de considerar a sua constituição orgânica e sua conexão com a natureza em geral (condições geológicas, climáticas, hidrográficas, etc). Esses pressupostos condicionam a produção, pelo homem, de seus próprios meios de existência. E "Ao produzirem seus meios de existência, os homens produzem, indiretamente, sua própria vida material" (MARX, 2005, p. 44).

A natureza dos meios de vida já encontrados pelo homem condicionam, portanto, a produção, pelo homem, de seus meios de vida. E produzir meios de vida não se refere apenas à vida física ou orgânica. Ao produzir seus meios de vida, a sua vida material, o homem está manifestando um determinado modo de vida. Dados os pressupostos existentes, o homem pode manifestar por vários modos o seu modo de vida: as condições não apenas limitam, mas possibilitam uma diversidade de modos de existência material. É verdade também que se fossem outros os pressupostos condicionantes, outras determinações de vida seriam possíveis. Ainda assim, as condições existentes condicionam, mas não são grilhões apenas, são patamares de liberdade também. Ao produzirem seus meios de vida, manifestando sua vida pela produção desses meios de vida, o homem se torna o que é: "Da maneira como os indivíduos manifestam sua vida, assim são eles. O que eles são coincide, portanto, com sua produção, tanto com o que produzem como com o modo como produzem" (MARX, 2005, p. 45). Logo, o homem é a sua produção, a sua manifestação de vida.

A produção humana depende das condições existentes, mas, uma vez produzidos seus meios de vida, estes passam também a funcionar como condições, uma vez que a estrutura social, o Estado nascem do processo vital dos indivíduos reais, mas, uma vez postos, condicionam a produção de vida pelos homens. E também a produção da consciência - real ou falsa - as ideias, as representações está vinculada ao comportamento material do homem. As forças produtivas, tal como se manifestam e tal como são condicionadas, produzem a

\footnotetext{
${ }^{2} \mathrm{O}$ manuscrito de A Ideologia Alemã foi concluída em 1846.
} 
linguagem, a política, o direito, a religião, a moral: “A consciência nunca pode ser outra coisa que o ser consciente, e o ser dos homens é o seu processo da vida real" (MARX, 2005, p. 51).

Ainda que nebulosas as formulações cerebrinas, elas são sublimações necessárias do processo vital humano, formuladas, portanto, sobre bases materiais, e não ideais. Por isso, a produção material e as relações materiais transformam, a partir da realidade, o pensar e seus produtos. Donde vem a Marx (2005, p. 52) sentenciar:

Não é a consciência que determina a vida, mas é a vida é que determina a consciência. Pela primeira maneira de considerar as coisas, parte-se da consciência como o próprio indivíduo vivo; pela segunda, que é a que corresponde à vida real, parte-se dos próprios indivíduos reais e vivos, e se considera a consciência unicamente com a sua consciência.

Pela exposição feita, já se poderia dessumir que a concepção marxiana jamais apontou para a subordinação do sujeito ao objeto, ou da consciência à realidade, pois a consciência é o ser consciente, ser que se manifesta em sua produção: consciência não é um produto que se separa do ser para a ele se subordinar lógica ou cronologicamente, ou sob qualquer perspectiva. A consciência - real, falsa - é parte da realidade do ser, é uma de suas manifestações e não se pode abstraí-la para subordiná-la a uma realidade distinta dela mesma. A consciência é a consciência de um indivíduo, de um ser que se manifesta materialmente e o pensar é uma dessas manifestações. Esquematicamente, temos:

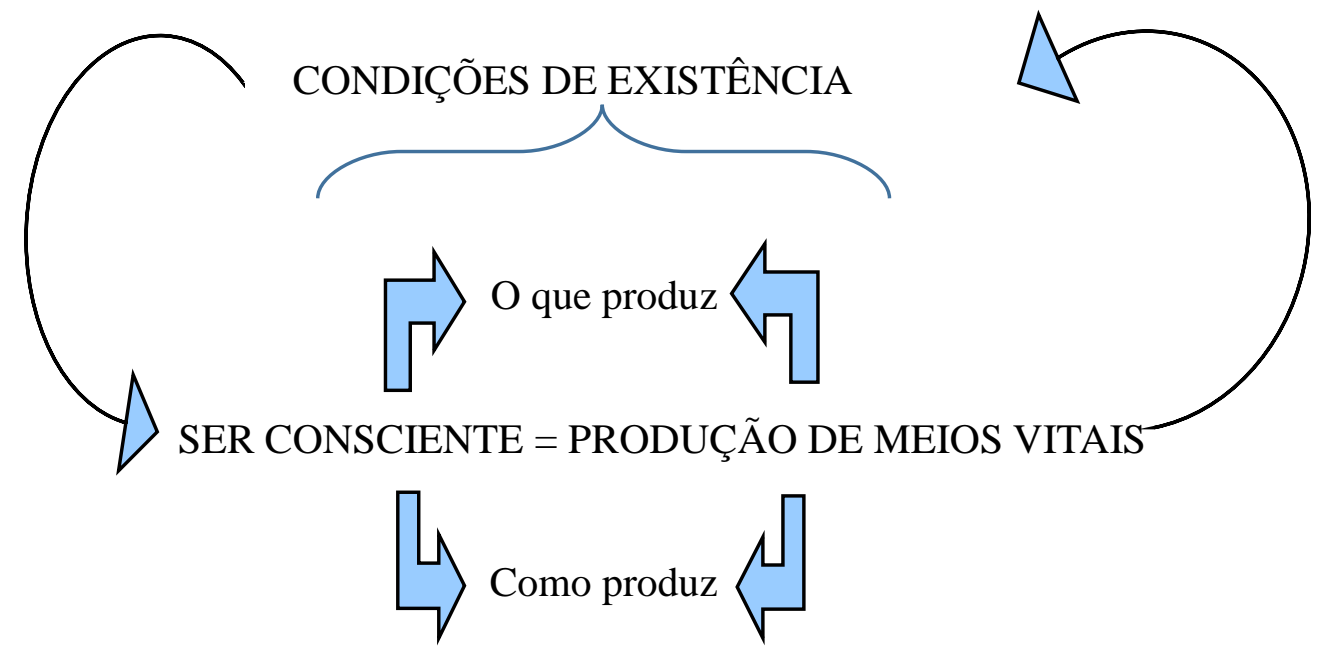

As condições de existência condicionam a produção vital do ser. O ser se produz ao produzir sua vida material. Sua produção é uma produção consciente, que se objetiva 
conscientemente. E sua produção recondiciona a existência de sua produção. O ser consciente se determina na exata medida do que produz e de como produz. E o que produz e como produz nada mais é do que o ser consciente. Quando se afirma que a consciência é um produto da vida, está a se afirmar que a consciência é o ser consciente produzido por sua produção. Logo, ao se afirmar que a vida produz a consciência não quer significar subordinação do sujeito ao objeto, mas que a consciência é sempre objetivada pela produção vital humana: “(...) podemos verificar que o homem tem também 'consciência'. Mas, assim mesmo, não significa consciência 'pura'. Desde o começo pesa sobre 'o espírito' a maldição de estar 'contaminado' pela matéria (...)" (MARX, 2005, p. 56).

Uma das características fundamentais da consciência é sua nota de sociabilidade. A consciência humana só pode emergir enquanto relação social humana: "A consciência, consequentemente, desde o início é um produto social, e o continuará sendo enquanto existirem homens" (MARX, 2005, p. 56). Só o homem é capaz de consciência, pois só o homem é capaz de relações. Lembra Marx (2005) que o animal não se relaciona com coisa alguma: sua relação não existe como relação para ele, animal. O animal coexiste, mas não se relaciona. Já o homem ao relacionar-se em sociedade, toma consciência de que vive em sociedade e de que tem necessidade de estabelecer relações com outros indivíduos. E toma consciência de que tem de manter relações com a natureza para produzir-se como tal. As relações humanas são condicionadas pelas relações do homem com a natureza e as relações humanas com a natureza se condiciona, pelas relações entre homens: "Logo se vê que essa religião natural, isto é, essas relações determinadas com a natureza, estão condicionadas pelo modo da sociedade e vice-versa" (MARX, 2005, p. 57).

A nota de sociabilidade da consciência é rica de consequências e por isso merece uma análise mais acurada. A sociabilidade humana só pode ser compreendida nesses termos: em comunhão com a natureza. Lembra Marx (2010) que a generidade do homem não decorre apenas de sua prática como objeto seu, mas também quando o homem se relaciona consigo, com sua generidade, como ser genérico universal. A vida genérica humana, em primeiro plano, consiste em sua relação com a natureza, pela qual o homem faz da natureza seu corpo inorgânico: "Que a vida física e mental do homem está interconectada com a natureza não tem outro sentido senão que a natureza está interconectada consigo mesma, pois o homem é uma parte da natureza" (MARX, 2010, P. 84). Por isso, quanto maior o domínio humano sobre a natureza - entenda-se domínio como exercício de sua atividade produtiva, não como dominação hierárquica - mais universal se torna o homem, em sua generidade: 
Assim como plantas, animais, pedras, ar, luz, etc., formam teoricamente uma parte da consciência humana, em parte como objetos da ciência natural, em parte como objetos da arte - sua natureza inorgânica, meios de vida espirituais, que ele tem de preparar prioritariamente para a fruição e para a digestão -, formam também praticamente uma parte da vida humana e da atividade humana (MARX, 2010, p. 84).

A universalidade do homem aparace justamente ao fazer da natureza inteira - de maneira universal - o seu corpo inorgânico, tanto quanto a natureza é “(...) um meio de vida imediato, quanto na medida em que ela é o objeto/matéria e o instrumento de sua atividade vital" (MARX, 2010, p. 84). A vida genérica humana é, entretanto, sua atividade produtiva, sua vida produtiva e é no modo em que exerce essa atividade produtiva que se encontra o caráter genérico humano e "(...) a atividade consciente livre é o caráter genérico do homem" (MARX, 2010, p. 84). Isso quer dizer que a generidade humana é sua atividade consciente, e sua atividade consciente só pode se dar na medida em que se objetiva em sua atividade sensível, vale dizer em sua atividade que exerce na natureza, sendo essa atividade consciente parte mesma da natureza:

O animal é imediatamente um com a sua atividade vital. Não se distingue dela. É ela. O homem faz da sua atividade vital mesma um objeto de sua vontade e de sua consciência. Ele tem atividade vital e consciente. Esta não é uma determinidade (Bestimmtheit) com a qual ele coincide imediatamente. A atividade vital consciente distingue o homem imediatamente da atividade vital do animal. Justamente, [e] só por isso, ele é um ser genérico. Ou ele somente é um ser consciente, isto é, a sua própria via lhe é objeto, precisamente porque é um ser genérico (MARX, 2010, p. 84).

A generidade universal humana é comprovada, por conseguinte, no engendrar prático da atividade humana, na sua permanente transformação da natureza. O ser genérico consciente do homem é um ser relacional, que se relaciona com sua generidade, o que só pode se dar na objetivação consciente da natureza:

Precisamente por isso, na elaboração do mundo objetivo [é que] o homem se confirma, em primeiro lugar e efetivamente, como ser genérico. Esta produção é a sua genérica operativa. Através dela a natureza aparece com a sua obra e a sua efetividade (Wirklichkeit). O objeto do trabalho é portanto a objetivação da vida genérica do homem: quando o homem se duplica não apenas na sua consciência, intelectual[mente], mas operativa, efetiva[mente], contemplando-se, por isso, a si mesmo num mundo criado por ele (MARX, 2010, p. 85). 
Mas ao confirmar-se como ser genérico por meio de sua produção operativa, o homem produz o próprio homem, tanto a si mesmo quanto seu alter, pois o objeto produzido é tanto o acionamento de sua individualidade, como também a sua própria existência para o outro (MARX, 2010). A sociabilidade é, por isso, a nota essencial do produzir humano, já que o homem produz de acordo com o modo de ser da sociedade, pois é "Só na comunidade com outros é que cada indivíduo encontra os mecanismos para desenvolver suas faculdades em todos os aspectos; é apenas na coletividade, portanto, que a liberdade pessoal se torna possível" (MARX, 2005, p. 112). A atividade produtiva humana tanto está condicionada pela sociedade como também a sociedade está condicionada pela atividade produtiva humana: o modo de ser da sociedade é o modo pelo qual o ser humano produz em sociedade. É por isso que

\begin{abstract}
A essência humana da natureza está, em primeiro lugar, para o homem social; pois é primeiro aqui que ela existe para ele na condição de elo com o homem, na condição de existência sua para o outro e do outro para ele; é primeiro aqui que ela existe como fundamento da sua própria existência humana, assim como também na condição de elemento vital da efetividade humana. É primeiro aqui que a sua existência natural se lhe tornou a sua existência humana e a natureza [se tornou] para ele o homem. Portanto, a sociedade é a unidade essencial completada (vollendete) do homem com a natureza, a verdadeira ressurreição da natureza, o naturalismo realizado do homem e o humanismo da natureza levado a efeito (MARX, 2010, p. 107).
\end{abstract}

Natureza e sociedade não estão em oposição. Em assim sendo, a natureza humana, a sua essência, só pode ser compreendida nesse contínuo processo de simbiose da sociedade com a natureza, pois é na naturalidade da sociedade e na sociabilidade da natureza que o homem se efetiva. E são nessas condições que a consciência humana emerge, como consciência concreta e social: “Como consciência genérica o homem confirma sua vida social real e apenas repete no pensar a sua existência efetiva, tal como, inversamente, o ser genérico se confirma na sua consciência genérica, e é, em sua universalidade como ser pensante, para si” (MARX, 2010, p. 107). A consciência genérica é, por conseguinte, o próprio ser objetivado em sua produção. Ela confirma o ser social na mesma medida em que se confirma no ser social. Reproduzir no pensar a sua existência efetiva não significa subordinação ao objeto, pois ela se manifesta no próprio ser objetivado e o ser objetivado se manifesta conscientemente, embora seu pensar possa reproduzir, de forma equivocada, a realidade que cerca o ser objetivado: "Pensar e ser são, portanto, certamente diferentes, mas [estão] ao mesmo tempo em unidade mútua" (MARX, 2010, p.1080). 
A unidade essencial entre pensar e ser introduz uma inexorável relação entre a consciência e a objetividade do ser. $\mathrm{O}$ homem manifesta-se conscientemente em sua objetividade e a sua objetividade manifesta-se em uma totalidade relacional vez que ela é a expressão da natureza social humana. Em sua famosa passagem de "O Capital”, Marx (1989) colaciona que o que distingue o pior arquiteto da melhor abelha - referindo-se à construção arquitetônica e a produção de uma colmeia - é que no fim do processo do trabalho (humano) aparece um resultado que já existia antes idealmente na imaginação do trabalhador. Ele não transforma apenas o material sobre o qual opera, mas também imprime ao material o projeto que tinha conscientemente em mira, que constitui a lei determinante do seu modo de operar e ao qual tem de subordinar sua vontade. O trabalho humano, com sua atividade prática, como essência humana, realiza uma finalidade preconcebida, não se destina à imediatidade, a uma necessidade contingente de existência, mas responde a um determinar-se, a um efetivar-se conscientemente, a reconhecer-se em sua obra como seu objeto. Por isso o ser consciente não se opõe ao objeto, mas manifesta-se objetivamente, se pratica em objetividade e o objeto lhe é o veículo de sua manifestação:

\footnotetext{
O homem se apropria da sua essência omnilateral de uma maneira omnilateral, portanto como um homem total. Cada uma das suas relações humanas com o mundo, portanto, como um homem total. Cada uma das suas relações humanas com o mundo, ver, ouvir, cheirar, degustar, sentir, pensar, intuir, perceber, querer, ser ativo, amar, enfim todos os órgãos da sua individualidade, assim como os órgãos comunitários, || VII | são no seu comportamento objetivo ou no seu comportamento para com o objeto a apropriação do mesmo, a apropriação da efetividade humana; seu comportamento para com o objeto é o acionamento da efetividade humana (por isso ela é precisamente tão multíplice (vielfach) quanto multíplices são as determinações essenciais e atividades humanas), eficiência humana e sofrimento humano, pois o sofrimento, humanamente apreendido, é uma autofruição do ser humano (MARX, 2010, p. 108).
}

Apropriar-se do objeto é socializá-lo, é inseri-lo no âmago da sociabilidade humana enquanto participante da objetividade do comportamento humano. É quando o objeto deixa de ter uma categorização puramente existencial para tornar-se relacional no âmbito do acionamento da efetividade humana e passa a caracterizar a objetividade humana, tanto em sua individualidade como também em sua generidade, e pode, assim, o homem universalizarse em uma totalidade de objetivação, movido pela sociabilidade:

Consequentemente, quando por um lado, para o homem em sociedade a efetividade objetiva (gegenständliche Wirklichkeit) se torna em toda parte efetividade das forças 
humanas (menschliche Wesenkräfte) enquanto efetividade humana e, por isso, efetividade de suas próprias forças essenciais, todos os objetos tornam-se [a] objetivação de si mesmo para ele, objetos que realizam e confirmam sua individualidade enquanto objetos seus, isto é, ele mesmo torna-se objeto (MARX, 2010, p. 110).

O homem em seu ser natural, físico, sensível, depende de objetos sensíveis que estão fora de si para efetivar-se, para objetivar-se. A realidade em que inserida o homem lhe serve de meio de sua objetivação consciente e o homem só pode se confirmar em objetividade sensível, sendo ele mesmo, homem efetivo, parte da realidade. O homem manifesta-se em objetos enquanto ser natural e social e assim confirma objetivamente sua generidade consciente, pois “Um ser não objetivo é um não-ser" (MARX, 2010, p. 127). Enquanto não se objetiva como homem, enquanto mero animal, o homem não se relaciona, nem consigo, nem com seu alter nem com objetos. É só no engendrar de sua efetividade, é só na prática de si mesmo como objeto seu, é confirmando-se objetivamente por meio de objetos sensíveis que o homem pode relacionar-se. E relacionar-se só pode ocorrer em sociedade, pois quando o homem se socializa se torna homem e seu objeto pode ser efetivar como ser social: "O homem só não se perde em seu objeto se este lhe vem a ser como objeto humano ou homem objetivo. Isto só é possível na medida em que ele vem a ser objeto social para ele, em que ele próprio se torna ser social, assim como a sociedade se torna ser para ele neste objeto" (MARX, 2010, p. 109). A relação com o objeto não é uma relação antagônica na qual o homem confronta o seu ser com o seu não-ser. A relação humana com o objeto é, antes, uma objetivação relacional, pela qual o homem se apropria do objeto como seu meio de efetivação e ele mesmo - homem - se objetiva no objeto:

O olho se tornou olho humano, da mesma forma como o seu objeto se tornou objeto social, humano, proveniente do homem para o homem. Por isso, imediatamente em sua práxis, os sentidos se tornam teoréticos. Relacionam-se com a coisa por querer a coisa, mas a coisa mesma é um comportamento humano objetivo consigo própria e com o homem, e vice-versa. Eu só posso, em termos práticos, relacionar-me humanamente com a coisa se a coisa se relaciona humanamente com o homem (MARX, 2010, p. 109).

Nesse ponto crucial, já é possível perceber que a relação cognitiva não é uma simplesmente a contraposição de um sujeito enredado em suas faculdades ideais de conhecer e um objeto que eventualmente tenha notas cognoscíveis. Mas é, sobretudo, uma objetivação relacional pela qual o homem se apropria do objeto, em sua prática, e dele toma consciência na mesma medida em que o toma para si, nele se confirmando. É um processo que se realiza 
em uma totalidade dialética em que natureza e sociedade estão plenamente articuladas, embora não intransigentemente definidas em sua forma de articulação e só pode ser definida em termos pragmáticos. A consciência, e o conhecimento, dependem sempre das condições materiais nas quais o homem pode objetivar-se, mais uma vez aqui reforçando que depender não significa subordinar-se: há uma recíproca dependência, pois a objetivação só pode se dar como objetivação consciente. Mas dependem também das condições sociais, ou melhor, das condições materiais socializadas, se quisermos assinalar a unidade essencial entre natureza e sociedade. Logo, o conhecimento não é, simplesmente, uma percepção subjetiva sobre um objeto. Se um indivíduo percebe um objeto com a coloração vermelha, isto se dá graças às condições físicas de seu aparelho de visão de traduzir os raios de luz dessa forma e a sua capacidade de aprendizado das cores, inclusive de nominá-la como tal. Mas e se outro indivíduo, daltônico, percebe o mesmo objeto com coloração verde, não teríamos uma outra verdade? Não seria a verdade diferente para ele? Não, nesse caso teríamos que um indivíduo daltônico, em razão de suas condições, percebe as cores de forma distinta da de um indivíduo sem essa característica. E a verdade, em sua totalidade, é que indivíduos podem perceber e aprender cores de acordo com suas capacidades físicas, sensíveis, naturais, sociais, culturais, etc: a verdade não é um produto de uma individualidade, nem é uma perspectiva puramente subjetiva e, embora dependa das condições materiais, essas condições devem ser tomadas em uma totalidade articulada. Por isso, após afirmar que não só no pensar, mas com todos os sentidos o homem é afirmado no mundo objetivo, Marx (2010, p. 110) deixa consignado que

\begin{abstract}
Por outro lado, subjetivamente apreendido: assim como a música desperta primeiramente o sentido musical do homem, assim como para o ouvido não musical a mais bela música não tem nenhum sentido, é nenhum objeto, porque o meu objeto só pode ser a confirmação de uma das minhas forças essenciais, portanto só pode ser para mim da maneira como a minha força essencial é para si como capacidade subjetiva, porque o sentido de um objeto para mim (só tem sentido para um sentido que lhe corresponda) vai precisamente tão longe quanto vai o meu sentido, por causa disso é que os sentidos do homem são sentidos outros que não os do não social; [é] apenas pela riqueza objetivamente desdobrada da essência humana que a riqueza da sensibilidade humana subjetiva, que um ouvido musical, um olho para a beleza da forma, em suma as fruições humanas todas se tornam sentidos capazes, sentidos que se confirmam como forças essenciais humanas, em parte recém-cultivados, em parte recém-engendrados. Pois não só os cinco sentidos, mas também os assim chamados sentidos espirituais, os sentidos práticos (vontade, amor, etc.), numa palavra o sentido humano, a humanidade dos sentidos, vem a ser primeiramente pela existência do seu objeto, pela natureza humanizada.
\end{abstract}

Aqui então se resolve a suposta oposição entre sujeito e objeto, seja pela perspectiva do sujeito, que subordina o objeto ao sujeito cognoscente, seja pela visão do marxismo 
ortodoxo, que subordina o sujeito ao objeto, seja ainda pela posição culturalista, que põe sujeito e objeto em mesmo patamar. O conhecimento não se faz pela oposição de sujeito e objeto, mas pelo processo prático de objetivação da consciência, em um contínuo processo de socialização da natureza e naturalização do social. O sujeito não se subordina ao objeto, mas se presenta objetivamente, e nem o objeto se subordina ao sujeito, vez que lhe é meio pelo qual o sujeito pode se confirmar. E nem há que se contrapor duas polaridades - sujeito e objeto em exigência recíproca, dada a unidade essencial que deve haver entre o ser social e sua objetividade, e que só pode se resolver em totalidade dialética, e não pela simples contraposição individual de um sujeito e de um objeto:

\footnotetext{
Vê-se como subjetivismo e objetivismo, espiritualismo e materialismo, atividade e sofrimento perdem a sua oposição apenas quando no estado social e, por causa disso, a sua existência enquanto tais oposições; vê-se como a própria resolução das oposições teóricas só é possível de um modo prático, só pela energia prática do homem e, por isso, a sua solução de maneira alguma é apenas uma tarefa do conhecimento, mas uma efetiva tarefa vital que a filosofia não pôde resolver, precisamente porque a tomou apenas como tarefa teórica (MARX, 2010, p. 111).
}

É nesse diapasão que pode ser compreendida a tarefa científica: uma tarefa prática de tomada de consciência na medida em que o homem pode, por meio dela, objetivar-se. A ciência é um empreendimento social, que se vale de instrumentos socialmente disponíveis, e auxiliam o homem a socializar-se, a socializar a sua natureza. Por isso Marx (2005) assinala que mesmo a ciência natural pura tem por material e finalidade graças ao comércio, à indústria e à atividade sensível do homem. A consciência não cria a realidade, mas se confirma na realidade. $\mathrm{O}$ homem existe na realidade e coexiste com os demais objetos até o ponto em que se socializa, socializa a natureza, socializa a sua natureza, deixa de apenas coexistir e passa a se relacionar num processo de objetivação consciente. É preciso reforçar que nem sempre esse esforço de consciência resultará na compreensão da realidade. Tanto a inconsciência como a falsa consciência fazem parte desse evolver objetivo. Uma falsa consciência não é proibitiva da objetivação humana, porém pode assinalar uma contradição insanável: "Todavia, ainda que essa teoria, essa teologia, essa filosofia e essa moral, etc., entrem em contradição com as relações sociais existentes, isso só é possível ocorrer porque as relações sociais existentes estão em contradição com as forças de produção existentes" (MARX, 2005, p. 58).

A incompreensão da realidade se dá quando se intenta desconectar a consciência da materialidade sensível, e em particular quando se tenta compreender essa realidade por sua 
fenomenologia, e não pela sua totalidade. A tentativa de se fazer ciência por um modelo idealista que contrapõe um sujeito cognoscente isolado do mundo, para supostamente manter sua objetividade, e um objeto que lhe é não só externo, como estranho, produz "ídolos" (abstrações, representações conceitos, dogmas, etc) que obnubilam a compreensão do real, pois tais abstrações “(...) são simplesmente a expressão espiritual idealista, a representação aparente do indivíduo isolado, a representação de grilhões e limites muito empíricos dentro dos quais se movem o modo de produção da vida e a forma de troca conectada" (MARX, 2005, p. 58). Mas mesmo a falsa consciência não deixa de ter sua importância, já que, por ela, pode se comprovar que o conteúdo consciente não se subordina à realidade, embora dela dependa. Basta lembrar que o geocentrismo serviu bem à prática humana por séculos, jamais impedindo o homem de efetivar-se.

A consciência não é uma tábula rasa na qual se possa imprimir o conteúdo fenomenológico, nem é o opaco espelho que reflete passivamente a realidade. Por isso a insistência de que a dependência não é subordinação, mas exigência, no caso exigência recíproca, ou dependência recíproca, pois tanto se depende da sensibilidade para se expressar conscientemente, como também só conscientemente se pode expressar o homem humanizado, e só na totalidade articulada da consciência objetivada é que se pode expressar a verdade, embora haja tanta falsa consciência pela vida:

Essa concepção de história se baseia no processo real de produção, partindo da produção material da vida imediata; e concebe a forma de troca conectada a esse modo de produção e por ele gerada de toda a história, apresentando-a em sua ação enquanto Estado e explicando a partir dela o conjunto dos diversos produtos teóricos e formas da consciência - religião, filosofia, moral, etc. - e seguindo seu processo de nascimento a partir dessas produções; o que permite então, naturalmente, expor a coisa em sua totalidade (e também analisar a ação recíproca entre os diferentes aspectos). (MARX, 2005, p. 65).

O conhecimento só pode ser concebido, portanto, em sua formulação pragmática, tanto pois se trata de uma prática social, como também porque deve ser ater à realidade em sua objetivação, sem que isso tenha algum caráter hierárquico, pois “(...) as circunstâncias fazem os homens assim como eles fazem as circunstâncias" (MARX, 2005, p. 66), não se podendo atribuir qualquer precedência lógica sobre sujeito ou objeto, mas sim considerar que o homem se positiva conscientemente em sua objetividade categórica, e por isso: 
frequência somente aspectos singulares, dessa sociedade determinada, desse sujeito, e que, por isso, a sociedade, também do ponto de vista científico, de modo algum só começa ali onde o discurso é sobre ela enquanto tal (MARX, 2011, p. 85).

O conhecimento científico é um modo particular de tomada de consciência, que se vale de um instrumental metodológico, e que tem por "objeto" não um objeto singular, mas a objetivação humana em sua totalidade dialeticamente articulada. Seu objeto é sempre a atividade sensível humana, atividade que toma a natureza como base, na medida em que ela mesma é integrante dessa natureza. É nesse sentido que Marx (2010, p. 74) consigna que o mundo sensível “(...) não é um objeto dado imediatamente, eterno por toda a eternidade, um objeto igual a si mesmo, mas sim o produto da indústria e do estado da sociedade". A ciência tem que determinar sua jornada em busca das categorias que expressam as formas do ser, não em sua aparência imediata, fenomenológica, mas sim em sua essência, ou seja, em sua correlação com a atividade humana sensível:

A sensibilidade (vide Feuerbach) tem de ser a base de toda ciência. Apenas quando esta parte daquela na dupla figura tanto da consciência sensível quanto da carência sensível - portanto apenas quando a ciência parte da natureza - ela é ciência efetiva. A fim de que o "homem" se torne objeto da consciência sensível e a carência do "homem enquanto homem" se torne necessidade (Bedürfnis), para isso a história inteira é a história da preparação / a história do desenvolvimento. A história mesma é uma parte efetiva da história natural, do devir da natureza até ao homem. Tanto a ciência natural se subsumirá mais tarde precisamente a ciência do homem quanto a ciência do homem subsumirá sob si a ciência natural; pois a natureza sensível imediata para o homem é imediatamente a sensibilidade humana (uma expressão idêntica), imediatamente como o homem outro existindo sensivelmente para ele; pois sua própria sensibilidade primeiramente existe por intermédio do outro homem enquanto sensibilidade humana para ele mesmo. Mas a natureza é o objeto imediato da ciência do homem. O primeiro objeto do homem - o homem - é natureza, sensibilidade, e as forças essenciais humanas sensíveis particulares; tal como encontram apenas em objetos naturais sua efetivação objetiva, [essas forças essenciais humanas] podem encontrar apenas na ciência do ser natural em geral seu conhecimento de si. O elemento do próprio pensar, o elemento da externação de vida do pensamento, a linguagem, é de natureza sensível. A efetividade social da natureza e a ciência natural humana ou a ciência natural do homem são expressões idênticas (MARX, 2010, p. 112).

O conhecimento científico não é uma polaridade sujeito-objeto. O objeto da ciência não é outra coisa senão essa intrincada relação entre homem e natureza - natureza humana ou humanidade da natureza - em seu devir pragmático, que se formula a partir do momento que o homem se socializa, ou seja, é a sensibilidade, concebida como a categorização do homem social na natureza. É como o homem se positiva na natureza, enquanto ser social, enquanto ser que se relaciona e enquanto ser que pensa. A ciência, como linguagem que é, é uma 
expressão dessa consciência prática que emerge na objetivação do homem. Se a linguagem é um produto social que surge da necessidade de socialização, a ciência é a necessidade de conhecer, que igualmente decorre de exigências sociais.

E o homem só conhece na medida em que se efetiva, sendo o conhecimento parte dessa efetividade. Não se trata de uma atividade à parte, pela qual um sujeito se insula em sua ilha transcendental e se submete a um frenesi de sensações hauridas em sua peregrinação cerebrina, quando se defronta com uma objetividade que lhe é estranha. A ciência é uma determinação, uma categorização do homem, uma forma humana que se exterioriza como efetividade do homem social, e seu objeto é a própria objetivação consciente do homem, em sua natureza social, em sua socialização da natureza, em sua universalidade, que se resolve numa totalidade dialeticamente articulada. Donde sobressai a observação empírica como atividade essencial do conhecimento (MARX, 2010) como forma de acesso às determinações do real. Qualquer que seja o método científico utilizado como meio de produção do conhecimento, não pode ele se desgarrar da referibilidade ao real, e daí porque a observação empírica é sempre parte essencial da pesquisa. Não se trata de retorno ao empirismo, com seu determinismo subordinante, mas sim considerar a realidade como material de todo conhecer, já que essa realidade é o material de todo ser. Quando se tenta arrancar a ciência da realidade, ela inexoravelmente se fragmenta. Tentar subordinar a realidade a conceitos, a uma categorização conceitual, em vez de considerar a categoria como parte integrante da realidade, corresponde a retirar-lhe o objeto. A fragmentação disciplinar da ciência é uma consequência desse processo de abstração. A eleição de categorias conceituais como base principiológica da qual decorreriam todas as demais premissas científicas põe a realidade entre parênteses, fazendo com que a ciência tenha sua expansão para dentro. Quanto mais se avança no conhecimento fragmentado, tanto mais esse fragmento se isola da realidade e dos demais ramos do conhecimento. A solução não está numa formulação interdisciplinar, como um sincretismo idiossincrático, uma soma de problemas. A solução está, antes, fazer com que a ciência retorne ao chão da realidade e se volte à totalidade humana.

\section{CONCLUSÕES}

Do exposto acima, pode-se concluir que, das três concepções tradicionais acerca do conhecimento, nenhuma delas é aceitável, pois pecam em ponto essencial: todas concebem o conhecimento como um produto de uma interação entre um sujeito e um objeto. Essa 
interação se dá por oposição entre um eu e uma objetividade estranha, no caso da filosofia do sujeito; se resolve em uma subsunção, na concepção tradicional marxista, que faz subordinar o sujeito ao objeto; ou ainda ocorre por uma polaridade entre um eu positivo e um objeto negativo que se atraem dialeticamente, numa composição ontognoseológica. Entretanto, sob uma concepção materialista, o conhecimento não é uma interação entre um sujeito singular e um objeto singular, mas antes uma produção social, uma determinação da generidade humana que se apresenta como objetivação consciente do devir humano, em sua natureza social. Neste caso, além de outras conclusões, pode-se também concluir que:

a) Todo conhecimento humano é uma produção social, que se apresenta pela concretude de sua expressão, como linguagem, com prática. Como produto social, o conhecimento não pode ser entendido como obra de um indivíduo isolado e insulado em seu mundo transcendental.

b) o conhecimento não se forma a partir de uma interação de um sujeito cognoscente e um objeto cognoscível, mas é a emergência consciente de um processo dialético de objetivação. O conhecimento não é uma abstração, mas uma atividade prática do homem.

c) No conhecimento, o objeto não se subordina ao sujeito, nem o sujeito se subsume ao objeto, não havendo hierarquia, pois tantos as circunstâncias fazem o homem como também o homem faz suas circunstâncias, sendo o homem mesmo as suas circunstâncias.

d) No processo de conhecimento não há polaridade entre sujeito cognoscente e objeto cognoscível, mas unidade essencial entre uma consciência que se objetiva e uma objetivação consciente. O conhecimento é uma manifestação de um processo relacional da generidade humana em sua objetivação universal como ser social.

e) Como produto social, o conhecimento é universal, decorrente da universalidade da generidade humana. O conhecimento do homem lhe é objeto, objeto de sua generidade.

f) O homem só conhece quando se torna homem, quando deixa de apenas existir e passa a se relacionar, quando deixa de ser puramente animal e converte sua natureza em natureza social. A conversão do animal em homem se dá pela sua efetivação, pela sua atividade sensível, pela transformação da natureza em sua natureza, em seu objeto, sendo também o homem objeto da natureza.

g) A consciência depende de condições de materiais - sem a ela se subordinar - para se objetivar, sua efetividade, como positivação humana, é sempre efetividade sensível, sendo ela mesma - consciência - parte da realidade. A consciência é uma manifestação objetiva da humanidade. 
h) O conteúdo da consciência pode não reproduzir a realidade, e o processo de conhecer está permeado de inconsciência e falsa consciência. A consciência não é uma tábula rasa na qual se imprimem os dados do real, nem é um opaco espelho da realidade.

i) A ciência é uma determinação do ser humano, uma forma de sua existência, uma maneira particular de sua manifestação, de sua efetividade. Tal como a consciência, a ciência pode laborar em erro. Uma concepção científica equivocada não impede o homem de se efetivar. Uma teoria científica equivocada pode persistir por séculos e refletindo-se no engendrar prático humano.

j) Todo método científico é um método social, um instrumento um meio de sua produção. Todo método encontra seus limites na própria sociedade. Todo método deve ser guiado pela observação empírica, se se pretende a obtenção da verdade.

1) A ciência, que se pretende acesso à realidade, deve ter por objeto a totalidade, uma articulação dialética do homem em sua universalidade, em sua generidade, em sua natureza humana. Totalidade não significa o todo, que a ciência deve reproduzir o todo em sua explicação, mas deve compreender toda a articulação em sua compreensão.

\section{REFERÊNCIAS}

FARIA, José Henrique de. Epistemologia Crítica: metodologia e interdisciplinaridade. In: Práticas da Interdisciplinaridade em Estudo e Pesquisa. Arlindo Philippi Jr. e Valdir Fernandes (editores). Barueri, SP: Manole, 2015.

FAZENDA. Ivani C. Antunes. Interdisciplinaridade: história, teoria e pesquisa. $7^{\mathrm{a}}$ ed. Campinas: Papirus, 1994.

FRIGOTTO, Gaudêncio. A Interdisciplinaridade como Necessidade e como Problema nas Ciências Sociais. Revista Ideação. v. 10 - $\mathrm{n}^{\mathrm{o}}$ 1, $1^{\circ}$ sem. 2008 Universidade Estadual do Oeste do Paraná. Campus de Foz do Iguaçu. Centro de Educação e Letras. Cascavel, PR, Edunioeste, n. 1, (1998- ).

FOUCAULT, Michel. As Palavras e as coisas. Tradução de Salma Tannus Muchail. $8^{\mathrm{a}}$ ed. São Paulo: Martins Fonstes, 2000.

HEGEL, Georg Wilhem Friederich. Fenomenologia do Espírito. $4^{\mathrm{a}}$ ed., parte 1 e 2. Petrópolis: Vozes, 1999.

JAPISSU, Hilton. Interdisciplinaridade e Patologia do Saber. Rio de Janeiro: Imago, 1976.

KANT. Imanuel. Crítica da Razão Pura. Tradução de Lucimar Coghi Anselmi e Fulvio Lubisco. São Paulo: Martin Claret, 2009. 
KOSIK, Karel. Dialética do Concreto. Tradução de Célia Neves e Alderico Toríbio. $2^{\mathrm{a}}$ ed., Rio de Janeiro: Paz e Terra, 1976.

LUKÁCS, Georg. Prolegômenos para uma Ontologia do Ser Social. Tradução de Lya Luft Rodinei Nascimento. São Paulo: Boitempo, 2010.

MARX, Karl. O Capital: crítica da economia política. Vol. I, Livro 1. 13 ${ }^{\mathrm{a}}$ ed., Tradução de Reginaldo Sant'Anna. Rio de Janeiro: Bertrand, 1989.

Ideologia Alemã. Tradução Frank Müller. São Paulo: Martin Claret, 2005.

Boitempo, 2010.

Manuscritos Econômico-filosóficos. Tradução de Jesus Ranieri. São Paulo:

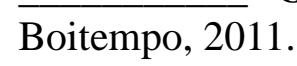

Grundisse. Tradução de Mario Duayer e Nélio Schneider. São Paulo:

PIAGET, Jean. Problemas Gerais de Investigação Interdisciplinar e Mecanismos Comuns. Tradução de Maria de Barros. Lisboa: Betrand, 1973.

REALE, Miguel. Filosofia do Direito. 16ª ed., São Paulo: Saraiva, 1994.

TONET, Ivo. Método Científico: uma abordagem ontológica. São Paulo: Instituto Lukács, 2013.

WEBER, Max. A “Objetividade do Conhecimento Científico. Tradução de Gabriel Cohn. São Paulo: Editora Àtica, 2006. 